\title{
A EXTRADIÇÃO A PARTIR DA LEI DE MIGRAÇÃO: CONSTRUÇÃO DE UM CENÁRIO DE COOPERAÇÃO JURÍDICA INTERNACIONAL À LUZ DOS DIREITOS HUMANOS?
}

\author{
Florisbal de Souza Del'Olmo ${ }^{1}$ \\ Diego Guilherme Rotta ${ }^{2}$
}

\begin{abstract}
Resumo: O artigo busca perfilar o instituto da extradição a partir da Lei de Migração e a sua relação com os direitos humanos. Utiliza-se o método dialético, com o emprego de revisão bibliográfica e documental enquanto procedimentos metodológicos. A partir de um recorte histórico, pretende-se destacar a fundamental importância da extradição enquanto medida de cooperação internacional entre os Estados-nação, possibilitando o exercício do jus puniendi e jus persequendi. Por fim, considerando a Lei n. ${ }^{\circ} 13.445 / 2017$, pretende-se destacar elementos do instituto que, eventualmente, conduzam ao entendimento de que a política migratória brasileira harmonizou-se com a vigente estrutura de direitos humanos.
\end{abstract}

Palavras-chave: Extradição; Lei de Migração; Cooperação Internacional; Direitos Humanos; Migrante.

\section{EXTRADITION ON THE MIGRATION LAW: CONSTRUCTION OF AN INTERNATIONAL LEGAL COOPERATION SCENARIO IN THE LIGHT OF HUMAN RIGHTS?}

\begin{abstract}
The article seeks to outline the extradition institute based on the Migration Law and its relation with the human rights. The dialectical method is used, with the application of bibliographical and documentary revision as methodological procedures. From a historical cut, it is intended to highlight the fundamental importance of extradition as a measure of international cooperation among nation-states, making it possible to exercise jus puniendi and jus persequendi. Finally, considering the Law 13.445/2017, it is intended to highlight elements of the Institute that eventually lead to the understanding that Brazilian immigration policy has harmonized with the existing human rights framework.
\end{abstract}

Keywords: Extradition; Migration Law; International Cooperation; Human Rights; Migrant.

\footnotetext{
${ }^{1}$ Pós-Doutor em Direito (UFSC). Doutor (UFRGS) e Mestre em Direito (UFSC). Especialista em Direito e em Educação. Graduação em Odontologia e Direito. Professor do Programa de Pós-Graduação Stricto Sensu Mestrado e Doutorado em Direito da URI, Santo Ângelo, RS. Líder do Grupo de Pesquisa registrado no $C N P q$ Tutela dos Direitos e sua Efetividade. Coordenador do Projeto de Pesquisa Direito Internacional do Trabalho e o resgate da dignidade e da cidadania. Endereço postal: Rua Lourenço Zaccaro, n. 1370, Centro, Nova Santa Rita/RS, Brasil, CEP 92480-000. E-mail: florisbaldelolmo@ gmail.com. ORCID ID: https://orcid.org/0000-00028070-2912.

${ }^{2}$ Mestre em Direito pelo Programa de Pós-Graduação Stricto Sensu em Direito da Universidade Regional Integrada do Alto Uruguai e das Missões (URI), campus Santo Ângelo. Endereço postal: Rua Tiradentes, n. 531, Bairro Santo Antônio, Cerro Largo/RS, Brasil, CEP 97900-000. E-mail: dg_rotta@hotmail.com. ORCID ID: https://orcid.org/0000-0003-1333-0028.
} 


\section{INTRODUÇÃO}

No modelo vestfaliano de sociedade internacional, pautado nas relações políticas entre Estados-nação soberanos, sem um organismo supraestatal regulador, a extradição se coloca como o mecanismo de cooperação internacional mais relevante e importante ao longo da história, respeitando os limites de atuação jurisdicional dos Estados na persecução e punição penal de agentes causadores de ilícitos penais e resguardar as prerrogativas de soberania de cada corpo estatal.

A partir da criação, no final da primeira metade do século XX, de uma estrutura de direitos humanos, formalizada em tratados e convenções (posteriormente internalizadas e recepcionadas pelas constituições dos Estados nacionais signatários), e materializada nos tribunais e comissões internacionais e regionais de proteção dos direitos humanos e punição dos seus perpetradores, bem como de um cenário de migrações cada vez mais complexo e em constante complexificação, a reestruturação das políticas migratórias e, consequentemente, das medidas de cooperação internacional, colocou-se como um processo obrigatório.

Nesse cenário, abraçando a redemocratização do País, a partir da promulgação da Constituição da República Federativa de 1988, o Brasil se inseriu como ator nesse processo, abandonando a herança ditatorial presente no Estatuto do Estrangeiro e galgando novos horizontes para o tratamento da questão migratória a partir da Lei de Migração, não deixando de trazer inovações, também, no campo de positivação das medidas de cooperação internacional.

Objetivando percorrer os caminhos brevemente traçados no aporte introdutório, a presente pesquisa realiza-se com base no método dialético, mediante a análise da dimensão da historicidade, da totalidade, a interação dos fenômenos, da contradição e transformação, possibilitando uma interpretação contextualizada com maior dinamicidade da realidade (PRODANOV e FREITAS, 2013). No tocante aos procedimentos metodológicos, empregouse a pesquisa bibliográfica e documental, devidamente explorada a partir da técnica da análise de conteúdo, com a organização do material colhido (pré-análise), o estudo dos referenciais teóricos colhidos (descrição analítica) e a relação do material referencial com as variáveis, totalidade e contexto dos temas analisados (interpretação referencial) (BARDIN, 1979). Para tanto, dividir-se-á o presente trabalho em duas partes.

A primeira parte do trabalho destinar-se-á à apresentação da evolução histórica do instituto da extradição, diferenciando-o dos demais institutos similares, demonstrando, ao 
final, a sua importância enquanto ferramenta de cooperação internacional entre os Estadosnação no cenário global contemporâneo.

Em um segundo momento, tomando por base o contexto e cenário de elaboração e vigência da Lei de Migração, bem como os seus princípios, diretrizes e os direitos fixados aos migrantes, pretende-se destacar elementos, alterações e inovações legislativas que, eventualmente, possam conduzir ao entendimento de que a política migratória brasileira e, mais especificamente, no tocante ao instituto da extradição, tenha garantido considerável harmonização com o sistema contemporâneo de direitos humanos.

\section{I - DA EXTRADIÇÃo ENQUANTO MEDIDA DE COOPERAÇÃO JURÍdICA INTERNACIONAL}

O sistema de cooperação internacional, tradicionalmente, possui como objeto "medidas judiciais ou administrativas relativas a atos no âmbito do processo com conexão internacional", para que, mediante atividade em conjunto, os Estados consigam efetivar o cumprimento de diligências, exercer o poder de persecução e punição penal fora do território e ou de sua jurisdição não deixando de respeitar os limites de soberania dos envolvidos (DEL'OLMO e JAEGER JUNIOR, 2017, p. 75 e 81).

Em um cenário de "intensificação das relações entre as nações e seus povos, seja no âmbito comercial, migratório ou informacional" que "demanda cada vez mais um Estado proativo e colaborativo", a cooperação jurídica internacional perfaz-se num terreno propício para "solicitar a outro país alguma medida judicial, investigativa ou administrativa necessária para um caso concreto em andamento" ou, mais precisamente, para um determinado processo (MINISTÉRIO DA JUSTIÇA). ${ }^{3}$ Conforme concluem Florisbal de Souza Del'Olmo e Augusto Jaeger Junior (2017, p. 78), contrariamente às ordens jurídicas internas dos países, as medidas de cooperação jurídica internacional deixam evidente que, "no plano internacional não há hierarquia na competência que os Estados se outorgam, mas igualdades dos sistemas", diante da "inexistência de organismo supraestatal, com atribuição para essa determinação".

Complementarmente, consonante manifestação do então Ministro José Eduardo Cardozo, à frente do Ministério da Justiça brasileiro quando da elaboração do Manual de

3 MINISTÉRIO DA JUSTIÇA. Disponível em: <http://justica.gov.br/sua-protecao/cooperacaointernacional/Cooperacao-juridica-internacional>. Acesso em: 21 jun. 2018. 
Extradição (2012, p. 11), a partir da experiência empírica, tem-se que a cooperação entre os Estados "é o veículo mais eficaz de enfrentamento e desarticulação" das atividades criminosas que se dão no plano internacional (corrupção, fraudes diversas, narcotráfico, tráfico de armas, tráfico de pessoas, entre outros), sendo importante o fortalecimento dos canais de comunicação e o trabalho coletivo, haja vista a corrente ineficácia da atividade unilateral dos estados. São os laços e compromissos internacionais, em uma natureza bilateral ou multilateral, que consistem na estrutura principal da cooperação internacional na supressão de crimes (STEFANOVSKA, 2016, p. 39).

Transparente, pois, a necessidade de uma atuação conjunta entre os Estados-nação para que possam efetivar e, consequentemente, respeitar a soberania e os limites dos próprios sistemas jurisdicionais, sobretudo na seara de combate e desarticulação às ações criminosas internacionais. Um dos resultados desse sentimento/necessidade de cooperação é a Convenção das Nações Unidas contra o Crime Organizado Transnacional, ou Convenção de Palermo, aprovada pela Assembleia-Geral da ONU aos 15 dias de novembro de 2000 (internalizada na legislação brasileira mediante o Decreto n. ${ }^{\circ}$ 5.015, de 12 de março de 2004).

Com relação à natureza, as medidas de cooperação jurídica internacional no âmbito do processo internacional são doutrinariamente definidas enquanto: a) medidas de cooperação jurisdicional/jurídica ou b) medidas de cooperação administrativa (DEL'OLMO e JAEGER JUNIOR, 2017, p. 76 e 81). Enquanto as medidas de cooperação na modalidade jurisdicional/jurídica são aquelas originadas de "medida judicial estrangeira, implicando provimento que dependa da manifestação do Poder Judiciário", a partir de seu órgão originariamente competente, as medidas administrativas de cooperação internacional, por sua vez, são relativas "a atos provenientes de autoridades administrativas que não envolvam a atuação jurisdicional do Estado", tendo um processamento simplificado e tramitando “mediante a atuação da autoridade central e dos órgãos nacionais" (idem).

Ainda, poderão as medidas de cooperação jurídica internacional ser classificadas a partir de sua iniciativa, sendo de cooperação ativa, "quando direcionada a uma autoridade estrangeira, para cumprimento no exterior, exigindo-se a observância e o conhecimento do direito do país ao qual o pedido é encaminhado" ou de cooperação passiva, "quando recepcionada por autoridades nacionais, para o processamento no Brasil, sendo necessária a observância do direito nacional e a submissão aos procedimentos nacionais obrigatórios, sejam judiciais ou administrativos" (DEL'OLMO e JAEGER JUNIOR, 2017, p. 76). Ou seja, 
em tal classificação, toma-se como ponto de diferenciação qual Estado exige e a qual Estado é exigido o cumprimento de uma determinada medida.

Dentre as medidas de cooperação jurídica internacional listadas pela doutrina, de regra, a extradição é considerada uma das instituições mais antigas, tradicionais, eficazes e eficientes na cooperação entre os Estados para a repressão de crimes internacionais (DEL'OLMO, 2007, p. 14; SERRANO, 2000, p. 15; MAZZUOLI, 2014, p. 787-788; MINISTÉRIO DA JUSTIÇA, 2012, p. 15; STEFANOVSKA, 2016, p. 39). Com relação à etimologia do termo "extradição", "parece provir da expressão latina ex traditione, conotando assim a traditio extra territorum, ou seja, a entrega de alguém de um território (Estado) a outro" (MAZZUOLI, 2014, p. 787).

Vesna Stefanovska (2016, p. 39, tradução nossa) afirma que a extradição foi "gradualmente evoluindo, passando por vários estágios de feudalismo, monarquia absolutista, e pelo crescimento de instituições parlamentares através das quais a própria organização do Estado passou", tendo, finalmente, se tornado uma "instituição genuinamente de direito público criminal na supressão da criminalidade comum dos sujeitos”.

Florisbal de Souza Del'Olmo (2007, p. 16-18) apresenta como principais momentos históricos com relação à extradição: a) tratado realizado entre egípcios e hititas, em 1291 a. C., que continha uma cláusula sobre a extradição de refugiados políticos, geralmente referido como a mais antiga manifestação escrita do instituto; b) enquanto mais antigo tratado moderno de extradição para presos comuns registrado, o firmado em 4 de março de 1376, entre Carlos V, da França, e o Conde de Savoia, entre França e os Países Baixos, respectivamente, "prevendo a entrega de delinquentes comuns e apresentando uma lista dos crime que ensejariam o instituto"; e c) O Tratado de Paz de Amiens, construído entre Espanha, França e Inglaterra, em 1802, que formatou o instituto da extradição nos rumos ainda seguidos contemporaneamente, tendo, inclusive, já afastado a aplicação da medida para a extradição de criminosos políticos, o que acabou, mais tarde, consagrando-se com "a lei belga de $1^{\circ}$ de outubro de 1833 , que excluiu de seu alcance, em termos definitivos, os criminosos políticos".

Contemporaneamente, pode-se definir a extradição como um processo, em que, a partir de solicitação do Estado interessado, terceiro Estado efetua a entrega de pessoa condenada ou acusada (réu em ação penal) no país requerente e devidamente competente para 
o julgamento do crime imputado, objetivando julgar os autores de ilícitos penal tipificados, ${ }^{4}$ "não sendo, em tese, admitida para processos de natureza administrativa, civil ou fiscal" (DEL'OLMO e KÄMPF, 2011, p. 35; DEL'OLMO e JAEGER JUNIOR, 2017, p. 134)

A extradição "encontra justificativa no princípio de justiça segundo o qual a ninguém é lícito subtrair-se às consequências das infrações penais que comete", colocando-se como "o ponto alto da cooperação penal entre os países para a repressão internacional de crimes”, em respeito à soberania dos Estados e à "aplicação judicial internacional do princípio da territorialidade" (MAZZUOLI, 2014, p. 788 e 790). Conforme sustenta Vesla Stefanovska (2016, p. 39-40 e p. 46), em um contexto de aumento da criminalidade internacional, somado à facilidade da mobilidade humana, a extradição é coloca-se como uma ferramenta de grande importância para garantir a aplicação da lei interna dos Estados, evitando que os fugitivos utilizem-se das fronteiras como meios de escapar da atividade jurisdicional.

Tendo em vista o objetivo de assegurar a persecução e a punição penal do agente criminoso, por parte do Estado competente, a extradição é uma "relação executiva", envolvendo, judicialmente, tanto o governo do Estado requerente da medida, que toma a iniciativa em razão da existência prévia de um processo penal, já finalizado ou ainda em curso ante a sua estrutura de Justiça, quando o governo do Estado requerido, ou "Estado de asilo" (no qual se encontra o pretenso ou condenado criminoso), que não possui, de regra, a prerrogativa de decidir sobre o atendimento do pedido extradicional antes do pronunciamento do órgão Judiciário local (REZEK, 2011, p. 230-231).

Dessa forma, a realização da extradição tem como pressuposto a existência de um processo penal, em razão de um crime, em tese, grave - não podendo, de outra banda, ser aplicada em casos de crimes políticos, delitos militares, de opinião e de imprensa (DEL'OLMO, 2007, p. 32-36), não servindo, simplesmente, para “a recuperação forçada do devedor relapso ou do chefe de família que emigra para desertar dos seus deveres de sustento da prole" (REZEK, 2011, p. 231).

Valerio de Oliveira Mazzuoli (2014, p. 790) destaca como condição básica para a concessão da extradição, além da existência de um processo penal em andamento (no Estado requerente da aplicação da medida), que o fato deverá ser tipificado enquanto fato criminoso em ambas as leis - no ordenamento do Estado requerente, bem como no Estado requerido -,

\footnotetext{
${ }^{4}$ Para Valerio de Oliveira Mazzuoli (2014, p. 790), a extradição "Não se trata de pena, mas de medida de cooperação internacional na repressão ao delito, que visa a boa administração da justiça penal”.
} 
sendo desimportante o nome atribuído ao tipo penal (nomem juris), condição essa conhecida como "princípio da identidade", "dupla incriminação" ou "incriminação recíproca".

Além das condições gerais mencionadas, bem como os demais requisitos e limites impostos pela legislação interna ${ }^{5}$ à aplicação do instituto, o processo de materialização da extradição decorre/depende da existência de tratado ${ }^{6}$ entre os países em causa, seja bilateral ou multilateral, ${ }^{7}$ ou de promessa de reciprocidade, desde que permitida pela legislação interna, hipótese que em vigora antes um dever moral do que jurídico (DEL'OLMO, 2007, p. 31; DEL'OLMO e JAEGER JUNIOR, 2017, p. 136; MAZZUOLI, 2014, p. 787-788; REZEK, 2011, p. 231-232). ${ }^{8}$

$\mathrm{Na}$ tradição dos meios de cooperação internacional, a extradição também poderá ser classificada a partir da forma de seu pedido ${ }^{9}$ ou a partir da finalidade da aplicação do instituto (MAZZUOLI, 2014, p. 791-792).

Com relação ao pedido, na mesma ordem da classificação geral das medidas de cooperação internacional, a doutrina brasileira classifica a extradição enquanto ativa, ${ }^{10}$ (em relação ao Estado que requer a aplicação da medida) quando o Estado brasileiro requer a outro país a entrega de pessoa sobre quem exista condenação criminal e que esteja foragida ou além dos limites de atuação da jurisdição brasileira, ou passiva ${ }^{11}$ ( a partir do ponto de vista do Estado onde se homizia a pessoa condenada) quando um Estado estrangeiro requer ao estado brasileiro a extradição de um indivíduo acusado ou condenado, em processo penal corrente ou já findo, respectivamente, sob a competência de jurisdição daquele Estado (DEL'OLMO, 2007, p. 47-48; MAZZUOLI, 2014, p. 791-792).

\footnotetext{
5 No caso brasileiro, por exemplo, como será visto, posteriormente, a extradição deverá correr a partir da adimplência dos requisitos dispostos nos Arts. 81 a 99 da Lei n. ${ }^{\circ} 13.445 / 2017$ e Arts. 262 a 280 do Decreto n. $^{\circ}$ 9.199, de 20 de novembro de 2017, bem como das normas dispostas nos tratados e convenções internacionais com relação à matéria.

${ }^{6}$ Para Mazzuoli (2014, p. 789), “Os tratados de extradição celebrados entre os Estados interessados não criam direito, que preexiste à extradição, mas apenas estabelecem as condições para a sua efetivação”.

7 De acordo com Thelma Thais Cavarzere (1995, p. 232), quando regulamentada em tratados bilaterais ou multilaterais, a extradição é tornada obrigatória nos termos convencionais ou em leis internas.

8 "O direito extradicional tem como fontes atuais as seguintes: $a$ ) os tratados internacionais de extradição, bem como em sua ausência (ou até mesmo em seu complemento), as declarações formais de reciprocidade; $b$ ) as leis sobre extradição; $c$ ) a jurisprudência; e $d$ ) os usos e costumes internacionais." (MAZZUOLI, 2014, p. 789).

9 Para Valerio de Oliveira Mazzuoli (2014, p. 787), contrariamente à deportação e expulsão, "não há na extradição qualquer iniciativa das autoridades locais (posto ser sempre requerida por outra potência estrangeira)". Dessa forma, "O Estado que envia o extraditando é o Estado requerido, e o que solicita a sua entrega, o Estado requerente”.

${ }^{10}$ Arts. 278 a 280 do Decreto n. ${ }^{\circ} 9.199 / 2017$.

11 Arts. 266 a 277 do Decreto n. 9.199/2017. Mazzuoli (2014, p. 791-792) sustenta que a extradição passiva "deve ser sempre requerida (com o consequente pedido de entrega) por outro Estado estrangeiro, não havendo extradição espontânea ou ex officio".
} 
No que tange à finalidade, a extradição poderá ser processual, instrutória, ou cognitiva, durante o trâmite do processo penal no país de origem, para fins de instrução e julgamento do processo incidente sobre o fugitivo, ou extradição executória, para efetivar/tornar possível o cumprimento de uma pena já imposta pelo Estado requerente e devidamente cumpridas todas as instâncias de julgamento, ou seja, para possibilitar a restrição de liberdade da pessoa condenada (idem). ${ }^{12}$

Justamente em razão da ausência de um organismo supraestatal com hierarquia superior às dos Estados-nação, apto à realização de atividades de coerção que rompam o bloqueio da soberania desses últimos, as medidas de cooperação internacional constituem mecanismo de relação política capaz de resguardar o direito de punir e perseguir penalmente sujeito criminoso que, eventualmente, tenha se evadido do território ou da jurisdição competentes para a sua punição e persecução.

No entanto, tendo em vista tratar-se a extradição de medida de cooperação internacional, de regra jurídica, que trata diretamente com a restrição da liberdade de ir e vir da pessoa extraditanda, logicamente há que pautar-se nos tratados e convenções de direitos humanos. Mesmo que tenha, em seu objetivo principal, o reforço do direito penal internacional na assistência dos Estados à persecução de violadores de sua legislação doméstica, a normatização do procedimento extradicional também objetiva a proteção, a garantia de que os direitos do fugitivo, do criminoso, não sejam ignorados (STEFANOVSKA, 2016, p. 40). ${ }^{13}$

É nessa linha de pensamento que a segunda parte deste artigo pretende destacar a relação entre a extradição, a partir da Lei de Migração, e os direitos humanos na aplicação e execução da referida medida de cooperação internacional.

\footnotetext{
${ }^{12}$ Art. 81, caput, da Lei de Migração.

${ }^{13}$ Considerando que a Convenção de Viena sobre o Direito dos Tratados, concluída em 23 de maio de 1969, internalizada no Brasil pelo Decreto n..$^{\circ}$ 7.030, de 14 de dezembro de 2009 (com reserva aos Arts. 25 e 66) determina, em sua parte inicial, que a própria normatização e desenvolvimento dos tratados internacionais deverá preservar os princípios de Direito internacional incorporados na Carta das Nações Unidos, bem como o respeito universal e observância dos direitos humanos e das liberdades fundamentais para todos, logicamente, não poderão esses ser violados na aplicação e execução dos tratados, como os que versam sobre a extradição de pessoas.
} 


\section{II - EXTRADIÇÃO A PARTIR DA LEI N. ${ }^{\circ}$ 13.445/2017: ALINHAMENTO À ESTRUTURA DE DIREITOS HUMANOS CONTEMPORÂNEA?}

No período de vigência da Lei n. ${ }^{\circ}$ 6.815/1980, a extradição, instituto historicamente tradicional nas relações interestatais, enquadrava-se como um dos meios de promoção compulsória da saída do "estrangeiro", mais relevante do que a própria deportação e a expulsão, especialmente em razão de proporcionar a colaboração internacional no "atendimento do interesse persecutório do Estado cuja lei foi violada pela pessoa requerida" (DEL'OLMO e KÄMPF, 2011).

Considerando tratar-se o Estatuto do Estrangeiro de legislação produzida e deixada como herança de um período de ditadura militar, de defesa do Estado e da nação a partir de uma Doutrina de Segurança Social, tratando o sujeito "estrangeiro" como um inimigo, não pertencente, tendo a sua presença em território brasileiro condicionada à ordem pública e aos interesses nacionais (KENICKE, 2016, p. 13-19). Consequentemente, no período de vigência do referido diploma legal, a preocupação com os procedimentos administrativos que envolviam a manutenção e a condução coercitiva do "estrangeiro" para além das fronteiras brasileiras era maior que a preocupação com a humanização do processo (DEL'OLMO e ROTTA, 2017, p. 203).

Em um cenário de redemocratização do país, sobretudo após a promulgação da Constituição da República Federativa do Brasil de 1988, que exigiu que o Estado e a sociedade brasileira fossem renovados, objetivando a promoção e garantia dos direitos fundamentais (KENICKE, 2016, p. 110), e de um maior influxo de migrantes, sobretudo no final da primeira década deste século, que reconheceram o país como um potencial local de reconstrução para suas vidas, "diante da considerável emergência e estabilização da economia brasileira após a crise econômica mundial de 2008/2009” (ROTTA, 2018, p. 164-169).

Como resultado desse moroso processo de repensar a política migratória brasileira, passando por projetos de lei (PL) não bem sucedidos na revogação do Estatuto do Estrangeiro (Projeto de Lei n. ${ }^{\circ}$ 1.813/1991 e o PL n. ${ }^{\circ} 5.655 / 2009$ ), tem-se a elaboração do PL n. ${ }^{\circ}$ 288/2013, numeração perante o Senado Federal, e PL n. ${ }^{\circ}$ 2.516/2015, perante a Câmara dos Deputados, convertidos na Lei 13.445, de 24 de maio de 2017, e publicada no Diário Oficial da União de 25 de maio do mesmo ano. Mesmo diante da série de vetos emanados pelo chefe 
do executivo (Mensagem n. ${ }^{\circ}$ 163, de 24 de maio de 2017), ${ }^{14}$ que distorceram, em grande parte, o texto originário (ROTTA, 2018, p. 169), o processo legislativo da Lei da Migração contou com a realização de uma série de audiências públicas, onde participaram órgãos e servidores públicos envolvidos com a política migratória, acadêmicos e especialistas no estudo do fenômeno migratório e das políticas migratórias, inclusive com a composição de uma Comissão de Especialistas, responsável pela elaboração do Anteprojeto da lei e, sobretudo, com instituições da sociedade civil com atuação na militância dos direitos dos migrantes (MORAES, 2016, p. 303).

Dotada de um forte espírito contra-hegemônico de direitos humanos, de resgate às pulsões de emancipação das pessoas (SANTOS e CHAUI, 2014; SÁNCHEZ RUBIO, 2010, p. 24-47) a Lei de Migração apresenta uma carga de princípios e diretrizes que se impõem à política migratória brasileira, dentre os quais se destacam a universalidade, indivisibilidade e interdependência dos direitos humanos, repúdio e prevenção à xenofobia, ao racismo e outras formas de discriminação, não criminalização da migração, acolhida humanitária, igualdade de tratamento e de oportunidade aos migrantes e familiares, acesso igualitário e livre a serviços, programas e benefícios sociais, bens públicos, educação, assistência jurídica integral pública, trabalho, moradia, serviço bancário e seguridade social, e cooperação internacional com Estados de origem, de trânsito e de destino de movimentos migratórios, a fim de garantir efetiva proteção aos direitos humanos do migrante (Art. $3^{\circ}$, incisos I, II, III, VI, IX, XI e XV); bem como uma série de direitos e garantias concedidos aos migrantes como a condição de igualdade com os nacionais, a inviolabilidade do direitos à vida, à liberdade, à igualdade, à segurança, à propriedade, a proteção dos direitos e liberdades civis, sociais, culturais e econômicos, a liberdade de circulação em território nacional e o acesso à educação pública (Art. $4^{\text {o }}$, caput, inciso I, II e X). ${ }^{15}$

A partir da Lei n. ${ }^{\circ} 13.445$, de 24 de maio de 2017, a extradição, conjuntamente com a transferência de execução da pena e a transferência de pessoa condenada, figura dentre as medidas de cooperação internacional ${ }^{16}$ previstas no Capítulo VIII do referido diploma legal,

\footnotetext{
${ }^{14}$ Disponível em: <http://www.planalto.gov.br/ccivil_03/_Ato2015-2018/2017/Msg/VEP-163.htm>. Acesso em: 21 ago. 2018.

${ }^{15}$ Conforme Sidney Guerra (2017, p. 92), a Lei n. ${ }^{\circ}$ 13.445/2017 foi produzida "em conformidade com o sentimento constitucional de 1988, que atribuiu valor à dignidade da pessoa humana e toda carga correspondente à proteção dos direitos humanos".

${ }^{16}$ Tal mudança de nomenclatura/classificação da extradição na nova legislação denota a própria mudança de espírito na transição de uma política migratória fundada em um momento de estado de exceção, de segurança nacional, para uma acepção humanista da migração, política adequada ao Estado democrático instaurado a partir da Constituição da República Federativa do Brasil, em 1988 (DEL'OLMO e JAEGER JUNIOR, 2017, p. 145).
} 
adequando-se às novas posturas de cooperação na busca de interesses comuns entre os Estados (DEL'OLMO, 2007, p. 214-215), no esforço de convergência no combate ao crime transnacional e à impunidade (MINISTÉRIO DA JUSTIÇA, 2012, p. 14) e, consequentemente, alinhando-se ao posicionamento de grande parte da doutrina com relação ao próprio caráter histórico do instituto. A extradição, regrada na Seção I, artigos 81 a 99, é subsidiariamente regulamentada pelo Decreto n. ${ }^{\circ}$ 9.199, de 20 de novembro de 2017, por atos administrativos internos das autoridades e órgãos competentes, bem como pelas normas estabelecidas em acordos bilaterais ou multilaterais de extradição em que o Brasil figura como signatário. $^{17}$

No ordenamento jurídico brasileiro, os mecanismos de cooperação internacional são, ainda, balizados, em suas modalidades jurisdicional ou administrativa, nas formas passiva ou ativa, pelos Artigos 26 a 41 da Lei n. ${ }^{\circ}$ 13.105, de 16 de março de 2015 (Novo Código de Processo Civil ${ }^{18}$ ) (DEL'OLMO e JAEGER JUNIOR, 2017, p. 81), impondo, no Art. 26 e incisos, a diretrizes de: a) respeito às garantias do devido processo legal no Estado requerente; b) igualdade de tratamento entre nacionais e estrangeiros, residentes ou não no Brasil, no tocante ao acesso à justiça e tramitação de processos, devendo ser assegurada a assistência judiciária às pessoas necessitadas; c) publicidade processual, a ser excetuada nos casos de sigilo previstos na legislação brasileira ou do Estado requerente; d) existência de autoridade

\footnotetext{
${ }^{17} \mathrm{Na}$ matéria de extradição, o Brasil mantém, atualmente, acordos com os seguintes Estados: 1) Angola (Decreto Legislativo n. ${ }^{\circ} 4$, de 2008); 2) Argentina (Tratado do Decreto Legislativo n. ${ }^{\circ} 62.979$, de 11 de julho de 1968); 3) Austrália (Decreto n. ${ }^{\circ} 2.010$, de 23 de setembro de 1996); 4) Bélgica (Decreto n. ${ }^{\circ} 41.909$, de 29 de julho de 1957); 5) Bolívia (Decreto n. ${ }^{\circ} 9.920$, de 8 de julho de 1942); 6) Canadá (Decreto n. ${ }^{\circ} 6.747$, de 22 de janeiro de 2009); 7) Chile (Decreto n. ${ }^{\circ} 1.888$, de 17 de agosto de 1937); 8) China (Decreto n. ${ }^{\circ} .431$, de 9 de abril de 2015); 9) Colômbia (Decreto n. ${ }^{\circ}$ 6.330, de 25 de setembro de 1940); 10) Coreia do Sul (Decreto n. ${ }^{\circ} 4.152$, de 7 de março de 2002); 11) Equador (Decreto n. ${ }^{\circ} 2.950$, de 8 de agosto de 1938); 12) Espanha (Decreto n. ${ }^{\circ} 99.340$, de 22 de junho de 1990); 13) Estados Unidos da América (Decreto n. ${ }^{\circ} 55.750$, de 11 de fevereiro de 1965); 14) França (Decreto n. ${ }^{\circ}$ 5.258, de 27 de outubro de 2004); 15) Itália (Decreto n. ${ }^{\circ} 863$, de 9 de julho de 1993); 16) Lituânia (Decreto n..$^{\circ}$ 4.528, de 16 de agosto de 1939); 17) Mercosul (Decreto n. ${ }^{\circ} 4.975$, de 30 de janeiro de 2004); 18) Mercosul, Bolívia e Chile (Decreto n. ${ }^{\circ} 5.867$, de 3 de agosto de 2006); 19) México (Decreto n. ${ }^{\circ} 2.535$, de 22 de março de 1938); 20) Paraguai (Decreto n. ${ }^{\circ}$ 16.925, de 27 de maio de 1925); 21) Peru (Decreto n. ${ }^{\circ} 5.853$, de 19 de julho de 2006); 22) Portugal (Decreto n. ${ }^{\circ} 1.325$, de 2 de dezembro de 1994); 23) Reino-Unido e Irlanda do Norte (Decreto n..$^{\circ}$ 2.347, de 10 de outubro de 1997); 24) República Dominicana (Decreto n. ${ }^{\circ} 6.738$, de 12 de janeiro de 2009); 25) Romênia (Decreto n. ${ }^{\circ} 6.512$, de 21 de julho de 2008); 26) Rússia (Decreto n. ${ }^{\circ} 6.056$, de 6 de março de 2007); 27) Suíça (Decreto n. ${ }^{\circ} 23.997$, de 13 de março de 1934); 28) Suriname, (Decreto n. ${ }^{\circ} 7.902$, de 4 de fevereiro de 2013); 29) Ucrânia (Decreto n. ${ }^{\circ} 5.938$, de 19 de outubro de 2006); 30) Uruguai (Decreto n. ${ }^{\circ}$ 13.414, de 18 de janeiro de 1919); e 31) Venezuela (Decreto n. ${ }^{\circ}$ 5.362, de 12 de março de 1940) (SUPREMO TRIBUNAL FEDERAL).

${ }^{18}$ As normas do Código de Processo Civil são aplicáveis subsidiariamente Processo Penal brasileiro, ante disposição do Art. $3^{\circ}$ do Decreto-Lei n. ${ }^{\circ} 3.689$, de 3 de outubro de 1941 (Código de Processo Penal), razão pela qual as observações quando da execução e/ou aplicação de eventual tratado de cooperação internacional deverão, também, guiar o andamento do processo penal que incida sobre pessoa migrante.
} 
central para a recepção e transmissão dos pedidos de cooperação; e e) espontaneidade na transmissão de informações às autoridades estrangeiras.

Almejando verificar eventual movimento de harmonização da Lei de Migração, no tocante à extradição, com a estrutura de tratados e convenções, comissões e tribunais, de proteção dos direitos humanos e punição daqueles que os afrontam/violam, far-se-á, neste momento, sem a pretensão de esgotar a totalidade da matéria, a análise de algumas alterações e inovações legislativas com relação à referida medida de cooperação internacional.

Ao normatizar sobre as hipóteses nas quais não será concedida a extradição, o Art. 82 da Lei n. ${ }^{\circ}$ 13.445/2017, ${ }^{19}$ além da reprodução das situações já regradas no Estatuto do Estrangeiro, trouxe importante alteração registrada no inciso IV e inovação no inciso IX. O inciso quarto do Art. 82 aumentou a limitação das hipóteses de aplicabilidade da extradição, devendo a lei brasileira impor ao crime pena igual ou maior a 2 (dois) anos, enquanto, no Estatuto do Estrangeiro, já se permitia a realização da medida nos casos em que a lei brasileira prescrevesse pena de prisão maior que 1 (um) ano. Por sua vez, o inciso nono inova ao apresentar a impossibilidade de concessão de extradição caso o indivíduo for beneficiário de refúgio ou de asilo territorial, ou suspendendo, até a decisão definitiva, qualquer processo de extradição pendente, em fase administrativa ou judicial, que for fundado nos fatos que alicerçam a concessão de refúgio pareando, assim, a legislação migratória com a previsão dos Arts. 33, 34 e $35^{20}$ Lei n. $^{\text {o } 9.474, ~ d e ~} 22$ de julho de 1997 (Estatuto dos Refugiados).

\footnotetext{
${ }^{19}$ Art. 82. Não se concederá a extradição quando: I - o indivíduo cuja extradição é solicitada ao Brasil for brasileiro nato; II - o fato que motivar o pedido não for considerado crime no Brasil ou no Estado requerente; III - o Brasil for competente, segundo suas leis, para julgar o crime imputado ao extraditando; IV - a lei brasileira impuser ao crime pena de prisão inferior a 2 (dois) anos; $\mathrm{V}$ - o extraditando estiver respondendo a processo ou já houver sido condenado ou absolvido no Brasil pelo mesmo fato em que se fundar o pedido; VI - a punibilidade estiver extinta pela prescrição, segundo a lei brasileira ou a do Estado requerente; VII - o fato constituir crime político ou de opinião; VIII - o extraditando tiver de responder, no Estado requerente, perante tribunal ou juízo de exceção; ou IX - o extraditando for beneficiário de refúgio, nos termos da Lei ${ }^{\circ} 9.474$, de 22 de julho de 1997, ou de asilo territorial. § 1o A previsão constante do inciso VII do caput não impedirá a extradição quando o fato constituir, principalmente, infração à lei penal comum ou quando o crime comum, conexo ao delito político, constituir o fato principal. $\S 2^{\circ}$ Caberá à autoridade judiciária competente a apreciação do caráter da infração. § 3 o Para determinação da incidência do disposto no inciso I, será observada, nos casos de aquisição de outra nacionalidade por naturalização, a anterioridade do fato gerador da extradição. $\S 4^{\circ}$ O Supremo Tribunal Federal poderá deixar de considerar crime político o atentado contra chefe de Estado ou quaisquer autoridades, bem como crime contra a humanidade, crime de guerra, crime de genocídio e terrorismo. $§ 5^{0}$ Admite-se a extradição de brasileiro naturalizado, nas hipóteses previstas na Constituição Federal.

${ }^{20}$ Art. 33. O reconhecimento da condição de refugiado obstará o seguimento de qualquer pedido de extradição baseado nos fatos que fundamentaram a concessão de refúgio. Art. 34. A solicitação de refúgio suspenderá, até decisão definitiva, qualquer processo de extradição pendente, em fase administrativa ou judicial, baseado nos fatos que fundamentaram a concessão de refúgio. Art. 35. Para efeito do cumprimento do disposto nos arts. 33 e 34 desta Lei, a solicitação de reconhecimento como refugiado será comunicada ao órgão onde tramitar o processo de extradição.
} 
Com relação à prisão cautelar durante o processo extradicional, a Lei de Migração inseriu a necessidade de que tal instrumento de restrição de liberdade seja requerido "com o objetivo de assegurar a executoriedade da medida de extradição", com pedido devidamente fundamentado (Artigo 84, caput e parágrafo primeiro), afastando, assim, a aplicação automática antes visualizada na vigência do Estatuto do Estrangeiro e no Regimento Interno do Supremo Tribunal Federal. ${ }^{21}$ Quando da vigência do Estatuto do Estrangeiro, a prisão cautelar era evento automático após o início do trâmite do processo extradicional, não sendo impostas maiores limitações e/ou necessidade de fundamentação quanto à imperiosidade de aplicação do instrumento de privação da liberdade, restando transparente o espírito de "preservação da segurança e interesses nacionais, com forte aporte de exercício soberano do estado" (ROTTA, 2018, p. 122), típico de um estado de exceção (ditadura militar), colocando o estrangeiro como um potencial inimigo.

Inobstante a possibilidade de manutenção do entendimento da prisão cautelar como pressuposto para o regular andamento do processo de extradição (MUZZI, 2017, p. 4), podese, também, sustentar que, a partir da Lei n. $^{\circ}$ 13.445, garante-se primazia ao tratamento humanitário, buscando contemplar a liberdade do migrante, a partir de um olhar que não torna crime o próprio ato da migração (Arts. $3^{\circ}$ e $4^{\circ}$, da Lei de Migração), apontando a aplicação de eventual medida de prisão cautelar como ultima ratio, em respeito à regra de privação da liberdade tão somente após o trânsito em julgado da sentença, nos termos do Art. $5^{\circ}$, inciso LXVI, da Constituição da República Federativa do Brasil de 1988 (não deixando de observar a necessidade de fundamentação dos pedidos e decisões judiciais, consonante dispositivo do Art. 93, inciso IX, da Lei Maior) (CABRAL e LEAL, 2018).

Ainda com relação à prisão cautelar, contrariamente ao Estatuto do Estrangeiro - em que, durante o processo de extradição, havia previsão de que a prisão do extraditando se dava até o julgamento final pelo Supremo Tribunal Federal (STF), (Art. 84, caput e parágrafo único) -, com a Lei n. ${ }^{\circ}$ 13.445/2017, durante o processo extradicional, poderá o STF, após oitiva do Ministério Público, determinar que o extraditando cumpra a pena de restrição de liberdade (primazia da liberdade), eventualmente imposta enquanto medida preventiva, em albergue ou prisão domiciliar, ou que responda ao processo em liberdade, desde que

\footnotetext{
${ }^{21}$ Forte numa legislação característica de um período não democrático, de vigência de uma Doutrina de Segurança Nacional, o Supremo Tribunal Federal elaborou, em seu Regimento Interno, o Art. 208 "Não terá andamento o pedido de extradição sem que o extraditando seja preso e colocado à disposição do Tribunal" e o Art. 213 "O extraditando permanecerá na prisão, à disposição do Tribunal, até o julgamento final”, dando, assim, margem ao entendimento pacífico da prisão do súdito enquanto pressuposto ao regular processamento da extradição em sua modalidade passiva.
} 
considerados a situação administrativa migratória, os antecedentes do extraditando, bem como as circunstâncias do caso, mediante a retenção do documento de viagem e a aplicação de outras medidas cautelares eventualmente necessárias até o julgamento da extradição ou a entrega do extraditando (Art. 86 da Lei de Migração).

No mesmo sentido de tratamento humanitário e preservação da liberdade do extraditando, o Art. 93 da Lei n..$^{\circ}$ 13.445/2017, apesar de reproduzir, parcialmente, a previsão correspondente da legislação revogada, determina que, caso o Estado requerente da extradição, no prazo de 60 (sessenta) dias contados da ciência de procedência do pedido, não efetue a retirada do extraditando do território nacional, será esse colocado em liberdade, não se olvidando da aplicação de outras medidas. Não há mais qualquer referência à aplicação de expulsão, se o motivo da extradição o recomendar, ao extraditando colocado em liberdade, como dispunha o Estatuto do Estrangeiro, podendo-se entender pela simples aplicação de medidas de retenção de documento de viagem ou outras medidas cautelares necessárias, que não a expulsão, até a entrega do extraditando, considerando, logicamente, a situação administrativa migratória, os antecedentes e as circunstâncias do caso concreto, nos termos do Art. 86 da Lei de Migração.

Com relação aos compromissos a serem assumidos pelo Estado requerente da extradição, dispostos no Art. 96 da Lei de Migração, ${ }^{22}$ além daqueles já normatizados pelo Estatuto do Estrangeiro e reproduzidos na nova legislação, importante inovação no seu inciso sexto, determinando que o Estado requerente da medida deverá tomar o compromisso de não submeter a pessoa extraditanda a tortura ou outros tratamentos ou penas cruéis, desumanas ou degradantes. Dessa forma, a Lei n. ${ }^{\circ} 13.445 / 2017$, no processo de entrega de pessoa em razão de extradição, atende às disposições do Art. 5 da Declaração Universal dos Direitos Humanos (DUDH), de 1948 ("Ninguém será submetido à tortura nem a tratamento ou castigo cruel, desumano ou degradante”.), ao conteúdo da Convenção Interamericana para Prevenir e Punir a Tortura, concluída em Cartagena, em 9 de dezembro de 1985 e internalizada pelo Decreto n. ${ }^{\circ}$ 98.386, de 9 de dezembro de 1989; e, também, à previsão do Art. 5º inciso III, da

\footnotetext{
${ }^{22}$ Art. 96. Não será efetivada a entrega do extraditando sem que o Estado requerente assuma o compromisso de: I - não submeter o extraditando a prisão ou processo por fato anterior ao pedido de extradição; II - computar o tempo da prisão que, no Brasil, foi imposta por força da extradição; III - comutar a pena corporal, perpétua ou de morte em pena privativa de liberdade, respeitado o limite máximo de cumprimento de 30 (trinta) anos; IV - não entregar o extraditando, sem consentimento do Brasil, a outro Estado que o reclame; V - não considerar qualquer motivo político para agravar a pena; e

VI - não submeter o extraditando a tortura ou a outros tratamentos ou penas cruéis, desumanos ou degradantes.
} 
Constituição da República Federativa do Brasil de 1988 (“Artigo $5^{\circ}$ [...] III - ninguém será submetido a tortura nem tratamento desumano ou degradante").

Considerando, que, além de conceder uma pletora de direitos e garantias aos migrantes (Art. $4^{\circ}$ e incisos), a Lei n. ${ }^{\circ}$ 13.445/2017 imprime à política migratória brasileira uma série de princípios e diretrizes, dentre os quais se destacam a "universalidade, indivisibilidade e interdependência dos direitos humanos"; a "não criminalização da migração"; a "acolhida humanitária", e a cooperação internacional dos Estados em prol da proteção dos direitos humanos do migrante (Art. $3^{\circ}$, incisos I, III, VI e XV, da Lei de Migração), a partir do movimento de alterações e inovação legislativas ilustrado

anteriormente, entende-se que a extradição se reveste de um caráter humanitário, ou que novas camadas de direitos humanos foram à medida de cooperação internacional, conferindo maior aproximação e/ou harmonização com a estrutura de tratados e convenções, cortes e tribunais de promoção e proteção dos direitos humanos.

\section{CONCLUSÃO}

A extradição, enquanto medida jurídica de cooperação internacional, revela-se um instrumento de histórica importância na proteção e manutenção do jus puniendi e jus persequendi dos Estados-nação no combate à criminalidade entre fronteiras, restando devidamente respeitados os limites jurisdicionais dos Estados e as suas respectivas soberanias em uma sociedade globalizada e desprovida de um organismo supraestatal de regulação.

Por tratar, diretamente, com a mediata ou imediata restrição da liberdade de ir e vir da pessoa, o processo extradicional deve levar em consideração a proteção dos direitos do extraditando, pautando-se nos tratados e convenções de direitos humanos.

Considerando tal necessidade, seguindo um movimento de redemocratização do País, sobretudo com a Constituição da República Federativa do Brasil de 1988 e de necessidade de reestruturação das políticas migratórias, a Lei n. ${ }^{\circ}$ 13.445/2017 (Lei de Migração), a partir da imposição de uma série de princípios e diretrizes, concessão de direitos e garantias aos migrantes, bem como alterações e inovações legislativas entende-se que a extradição se revestiu de um caráter humanitário, colocando-se como medida de cooperação jurídica harmonizada com a estrutura de tratados e convenções, cortes e tribunais de promoção e proteção dos direitos humanos. 


\section{REFERÊNCIAS}

ARAÚJO, Luís Ivani de Amorim. Curso de direito dos conflitos interespaciais. Rio de Janeiro: Forense, 2002.

BARDIN, Laurence. Análise de conteúdo. Tradução Luiz Antero Reto e Augusto Pinheiro. Lisboa: Edições 70, 1979.

BEDIN, Gilmar Antonio. A sociedade internacional clássica: aspectos históricos e teóricos. Ijuí: Ed. Unijuí, 2011.

BRASIL. Constituição da República Federativa do Brasil de 1988. Disponível em: <http://www.planalto.gov.br/ccivil_03/constituicao/constituicao.htm>. Acesso em: 31 jul. 2018.

Lei n. ${ }^{\circ}$ 6.815, de 19 de agosto de 1980. Disponível em: <http://www.planalto.gov.br/ccivil_03/Leis/L6815.htm>. Acesso em: 31 jul. 2018.

Lei n. ${ }^{\circ}$ 9.474, de 22 de julho de 1997. Disponível em:

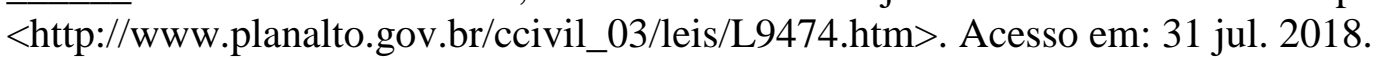

Decreto n. ${ }^{\circ}$ 5.015, de 12 de março de 2004. Disponível em: <http://www.planalto.gov.br/ccivil_03/_ato2004-2006/2004/decreto/d5015.htm>. Acesso em: 31 de jul. 2018.

Decreto n. ${ }^{0}$ 7.030, de 14 de dezembro de 2009. Disponível em: <http://www.planalto.gov.br/ccivil_03/_ato2007-2010/2009/decreto/d7030.htm>. Acesso em: 31 jul. 2018.

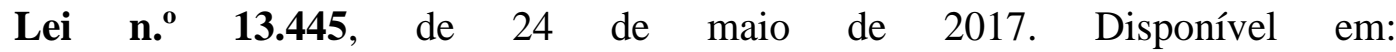
<http://www.planalto.gov.br/ccivil_03/_ato2015-2018/2017/lei/L13445.htm>. Acesso em: 31 jul. 2018.

CABRAL, Alan Kardec; LEAL, Rogério. A prisão cautelar à luz da nova lei de migração. In: Empório do Direito. 23 mar. 2018. Disponível em: <http://emporiododireito.com.br/leitura/a-prisao-cautelar-a-luz-da-nova-lei-de-migracao>. Acesso em: 30 jul.. 2018.

CÂMARA DOS DEPUTADOS. Decreto n. 9.199, de 20 de novembro de 2017. Disponível em: < http://www2.camara.leg.br/legin/fed/decret/2017/decreto-9199-20-novembro-2017785772-publicacaooriginal-154263-pe.html>. Acesso em: 31 jul. 2018.

CAVARZERE, Thelma Thais. Direito internacional da pessoa humana: a circulação internacional de pessoas. Rio de Janeiro: Renovar, 1995.

DEL'OLMO, Florisbal de Souza; JAEGER JUNIOR, Augusto. Curso de direito internacional privado. 12. ed. rev., atual. e ampl. Rio de Janeiro: Forense, 2017. 
DEL'OLMO, Florisbal de Souza; KÄMPF, Elisa Cerioli Del'Olmo. A Extradição no Direito Brasileiro. Rio de Janeiro: GZ Editora, 2011.

DEL'OLMO, Florisbal de Souza. A extradição no alvorecer do século XXI. Rio de Janeiro: Renovar, 2007, p. 214-215.

DEL'OLMO, Florisbal de Souza; ROTTA, Diego Guilherme. Da internacionalização à internalização: lei de migração e a busca de uma concepção "contra-hegemônica" de direitos humanos. In: BEDIN, Gilmar Antonio; SILVEIRA, Vladmir Oliveira da; GROTH, Terrie R. (coords.). Direito Internacional dos direitos humanos II [Recurso eletrônico on-line]. Organização CONPEDI. Florianópolis: CONPEDI, 2017, p. 192-209. Disponível em: <https://www.conpedi.org.br/publicacoes/roj0xn13/46i41956/ksiiDvdZX3gDMpmh.pdf>.

Acesso em: 30 ago. 2017.

GUERRA, Sidney. Alguns aspectos sobre a situação jurídica do não nacional no Brasil: da lei do estrangeiro à nova lei de migração. In: Direito em Debate, Ano XXVI, n. ${ }^{\circ} 47$, jan.-jun. 2017, p. 90-112.

KENICKE, Pedro Henrique Galotti. O estatuto do estrangeiro e a lei de migrações: entre a doutrina da segurança nacional e o desenvolvimento humano. Dissertação (Mestrado em Direito). Universidade Federal do Paraná. Curitiba, 2016. Disponível em: <http://acervodigital.ufpr.br/handle/1884/42884>. Acesso em: 01 nov. 2017.

MAZZUOLLI, Valério de Oliveira. Curso de Direito Internacional Público. 8. ed., rev., atual. e ampl. São Paulo: Editora Revista dos Tribunais, 2014.

MINISTÉRIO DA JUSTIÇA. Cooperação Jurídica Internacional. Disponível em: <http://www.justica.gov.br/sua-protecao/cooperacao-internacional>. Acesso em: 29 jul. 2018.

Extradição. Disponível em: <http://justica.gov.br/sua-protecao/cooperacaointernacional/extradicao>. Acesso em: 29 jul. 2018.

MINISTÉRIO DA JUSTIÇA. Manual de extradição. Brasília: Secretaria Nacional de Justiça. Departamento de Estrangeiros, 2012.

MORAES, Ana Luiza Zago de. Crimigração: a relação entre política migratória e política criminal no Brasil. Tese (Doutorado). Pontifícia Universidade Católica do Rio Grande do Sul, Faculdade de Direito, Programa de Pós-gradução em Ciências Criminais, Porto Alegre, 2016. Disponível em: <https://www.capes.gov.br/images/stories/download/pct/2016/MencoesHonrosas/Direito-Ana-Moraes.PDF>. Acesso em: 09 de nov. 2017.

MUZZI, Tácio. Os mecanismos de cooperação jurídica internacional na nova lei de migração. Extradição, transferência de execução da pena (TEP) e transferência de pessoas condenadas (TPC). In: Cooperação em Pauta, n. 30, Ago. 2017, p. 4. Disponível em: <http://www.justica.gov.br/sua-protecao/lavagem-de-dinheiro/institucional-

2/publicacoes/cooperacao-em-pauta/cooperacao-em-pauta-n30>. Acesso em: 18 jun. 2018.

POLIDO, Fabrício. Direito processual internacional e o contencioso internacional privado. Curitiba: Juruá, 2013. 
PRODANOV, Cleber Cristiano; FREITAS, Ernani Cesar de. Metodologia do trabalho científico: métodos e técnicas da pesquisa e do trabalho acadêmico. 2. ed. Novo Hamburgo: Feevale, 2013.

REZEK, José Francisco. Direito internacional público: curso elementar. 13. ed., rev., aum. e atual. São Paulo: Saraiva, 2011.

RODAS, Francisco Cortés; RAMÍREZ, Felipe Piedrahita. De Westfalia a Cosmópolis. Soberanía, ciudadanía, derechos humanos y justicia económica global. Siglo del Hombre Editores. Instituto de Filosofía de la Universidad de Antioquia, 2011.

ROTTA, Diego Guilherme. O migrante no contexto da política migratória brasileira: perspectivas de acesso à cidadania em um cenário de (re)fechamento de fronteiras. Dissertação (Mestrado em Direito). Programa de Pós-Graduação Stricto Sensu em Direito, Mestrado e Doutorado, Universidade Regional Integrada do Alto Uruguai e das Missões, Campus Santo Ângelo/RS, 2018.

SÁNCHEZ RUBIO, David. Fazendo e desfazendo direitos humanos. Tradução Clovis Gorczevski. Santa Cruz do Sul: Edunisc, 2010.

SANTOS, Boaventura de Sousa; CHAUI, Marilena. Direitos humanos, democracia e desenvolvimento. Versão e-book. São Paulo: Cortez, 2014.

SERRANO, Mário Mendes. Extradição: regime e práxis. In: BUCHO, José Manuel da Cruz et al. Cooperação internacional penal. Vol. I. Lisboa: Centro de Estudos Judiciários.

SPRANDEL, Marcia Anita. Migração e crime: a Lei 6.815, de 1980. REMHU, Rev. Interdiscip. Mobil. Hum., Brasília , v. 23, n. 45, p. 145-168, Dec. 2015. Disponível em: $<$ http://www.scielo.br/scielo.php?script=sci_arttext\&pid=S 198085852015000200145\&lng=en\&nrm=iso>. Acesso em: 31 jul. 2018.

STEFANOVSKA, Vesla. Extradition as a tool for inter-state cooperation: resolving issues about the obligation to extradite. In: Journal of Liberty and International Affairs, vol. 2, n. 1, 2016, p. 38-48. Disponível em: 〈http://e-jlia.com/papers/5_3.pdf〉. Acesso em: 20 jul. 2018.

SUPREMO TRIBUNAL FEDERAL. Tratados de extradição. Disponível em: $<$ http://stf.jus.br/portal/cms/verTexto.asp?servico=legislacaoTratadoExtradicaoTextual\&pagi na=IndiceTratadoExtradicao $>$. Acesso em: 30 jul. 2018.

UNESCO. Declaração universal dos direitos humanos. Disponível em: <http://unesdoc.unesco.org/images/0013/001394/139423por.pdf>. Acesso em: 20 jul. 2018.

UNODC, United Nations Office on Drugs and Crime. Manual on Mutual Legal Assistance and Extradition. United Nations Office on Drugs and Crime (Vienna). New York, United Nations, 2012. Disponível em: <https://www.unodc.org/documents/organizedcrime/Publications/Mutual_Legal_Assistance_Ebook_E.pdf>. Acesso em: 31 jul. 2018. 
Convenção das Nações Unidas contra o Crime Organizado Transnacional. Prevenção ao Crime e Justiça Criminal: marco legal. Disponível em: <https://www.unodc.org/lpo-brazil/pt/crime/marco-legal.html>. Acesso em: 31 jul. 2018. 